\title{
Barriers to Utilization of Postnatal Care: A Qualitative Study in Guinea
}

\section{Mamadou Dioulde Balde1, Aissatou Diallo', Anne Marie Soumah', Alpha Oumar Sall1, Boubacar Alpha Diallo², Fanta Barry' ${ }^{1}$ Amadou Oury Touré1, Alpha Amadou Barry', Sadan Camara1}

${ }^{1}$ Center for Research in Reproductive Health/Cellule de recherche en santé de la reproduction en Guinée (CERREGUI), Conakry, Guinée

${ }^{2}$ University Hospital Donka, Clinic of Gynecology and Obstetrics, Conakry, Guinea

Email: baldemddka@gmail.com

How to cite this paper: Balde, M.D., Diallo, A., Soumah, A.M., Sall, A.O., Diallo, B.A., Barry, F., Touré, A.O., Barry, A.A. and Camara, S. (2021) Barriers to Utilization of Postnatal Care: A Qualitative Study in Guinea. Open Journal of Obstetrics and Gynecology, 11, 391-402.

https://doi.org/10.4236/ojog.2021.114039

Received: March 20, 2021

Accepted: April 22, 2021

Published: April 25, 2021

Copyright $\odot 2021$ by author(s) and Scientific Research Publishing Inc. This work is licensed under the Creative Commons Attribution International License (CC BY 4.0).

http://creativecommons.org/licenses/by/4.0/

\begin{abstract}
Maternal mortality remains very high in developing countries. In Guinea, it is 550 maternal deaths in 100.000 living birth. More than half of these deaths occur in the postpartum period. Hence the interests to have a better understanding of the factors that hinder the realization of post-natal care (PNC) arise. It is for this reason that the objective of this study is to identify barriers to the use of post-natal care in Guinea. Methods: A qualitative study was conducted in the prefectures of Kindia and Dubréka, in the Administrative Region of Kindia (Guinea) in April and May 2014. Fourteen focus group discussions of women and girls of the community, as well as fifteen individual in-depth interviews ( 9 with women and 6 with healthcare providers). Results: Most women do their PNC during their child vaccination or in case of postpartum complications. Financial constraints are the main barrier to using postnatal care identified by participants. In general, distance from the health center associated with lack of transport mean and insufficient staffs are factors related to the health system. In addition, poor reception of clients, women's experience during childbirth, poor programming for PNC as well as the lack of trust and confidentiality between clients and health care providers are the barriers related to health providers. The participants also mentioned the lack of sensitization and information as well as cultural constraints as barriers to using post-natal care. Conclusion: The removal of these barriers in the use of PNC will significantly reduce maternal and neonatal mortality in Guinea.
\end{abstract}

\section{Keywords}

Barriers, Postnatal Consultation, Maternal Mortality, Guinea 


\section{Introduction}

High maternal mortality during pregnancy, childbirth and post-partum are heavy load in low-income countries. Thus, Sub-Saharan Africa has the highest maternal mortality rate in any region of the world (546 per 100,000 live births) [1]. In Guinea, it is 550 deaths per 100,000 living births [2]. More than $60 \%$ of maternal deaths in the world occur during the postpartum period-defined by the World Health Organization as the period starting one hour after placenta delivery and carry on until 6 weeks (42 days) after childbirth [3]. Despite the postpartum consultation being one of the recommended strategies to reduce maternal and neonatal mortality in the postpartum period, few women and newborns receive this service. In Ethiopia, only $17 \%$ of women receive at least one postnatal care service from a health facility within the first 48 hours after childbirth, against $43 \%$ in Malawi [4] [5].

In Guinea, post-natal care (PNC) ought to be performed during the first 6 weeks after childbirth. It includes information and communication, preventive and curative care for newborns and mothers [6]. The Guinean Demographic and Health Survey (DHS) of 2018 revealed that only $49 \%$ of women who gave birth had a postnatal examination in the 2 first days after birth, with a noticeable difference between urban and rural areas (68\% in urban areas versus $41 \%$ in rural areas). It ought to be noted that women who gave birth in a health facility have received more postnatal care in the first 2 days after childbirth than those who gave birth elsewhere (70\% versus $23 \%$ ). Among newborns, $43 \%$ received postnatal care in the first two days (66\% in urban areas versus 34\% in rural areas) [2]. These data highlight the importance of PNC for mother and child's health in Guinea. Hence the urgent need to carry out a study on barriers to the use of postnatal consultation services.

\subsection{Aim of the Study}

The aim of the study is to identify barriers to the use of postnatal consultation services in Guinea.

\subsection{Study Frame}

Guinea is located on the West African coast and has 11,663,627 inhabitants. The country is divided into four natural regions and seven administrative regions and the country's capital (Conakry). Health statistics slightly show that more than half of living births (53\%) occur in health facilities, with a higher frequency in urban areas than in rural areas ( $84 \%$ versus $40 \%$ ). So $55 \%$ were births assisted by skilled health care providers [2].

\section{Methods}

It is a qualitative study of transversal type carried out to women using postnatal care services aged between 15 and 49 and health care providers. To ensure a socio-cultural characteristic similarity, the prefectures of Kindia and Dubreka were 
randomly drawn in the Administrative Region of Kindia. A representative sample of all health facilities offering postnatal care was selected, one hospital and two rural health centers in each of the two target prefectures. A random draw using a software program was used to select a provider from the overall list of PNC providers in the selected health centers. The same procedure was used to randomly select the women who came for the postnatal care.

Focus group participants were identified with the support of local and Women Association managers.

\subsection{Data Collection's Techniques}

For data collection, fourteen focus group discussions with women and girls from the community (8 in rural areas and 6 in urban areas) and 15 individual in-depth interviews (9 with women and 6 with health care providers) were conducted in April and May 2014.

The focus group and individual in-depth interview guides focused on the attendance of health facilities for postnatal care and the reasons that prevent women from using these PNC services.

\subsection{Data Analysis}

Data were analyzed in accordance with the strategic assessment technique developed by WHO/HRP [7].

\subsection{Ethical Aspect}

The study was validated by the health research ethics committee in Guinea. The informed consent of participants and the confidentiality of information were guaranteed in all respects throughout the process.

\section{Results}

Table 1 shows participants' number (142) dispatched in 14 focus group discussions (FGD) with women and 15 individual in-depth interviews (IDI) with women and health care providers were carried out. The socio-demographic characteristics of FGD participants showed that $1 / 3$ were adolescents aged $15-19$, nearly three quarters were married; $48 \%$ had no educational level and $39.4 \%$ were traders. The IDI participants were mostly young women aged 20 - 24, married, not schooled, and household wives (Table 2). The health care providers were mostly aged more than 35 .

\subsection{Attendance of Post-Natal Care Services}

It focuses on the scope, motivation and women's accompaniment. According to participants, most women do their postnatal care (PNC) at the time of their child's vaccination. Except in case of complications where women who give birth are accompanied by their husbands or a family member, it ought to be noted that in case, women come alone for the PNC, as these quotes illustrate: 
Table 1. Distribution of participants according to collection tools.

\begin{tabular}{cccc}
\hline & $\mathrm{U}$ & $\mathrm{R}$ & Total \\
\hline Focus Groups discussion & 2 & & \\
Married girls aged 15 - 24 years & 2 & 2 & 4 \\
Unmarried girls aged 15 - 24 years & 2 & 2 & 4 \\
Married women aged 25 - 49 years & 6 & 4 & 6 \\
TOTAL & & 8 & 14 \\
Individual in-depth interview & 4 & 5 & 9 \\
Women users of PNC services & 2 & 4 & 6 \\
Health care providers & 6 & 9 & 15 \\
TOTAL & & & \\
\hline
\end{tabular}

Table 2. Socio-demographic characteristics of participants FGD and IDI Barriers to using PNC.

\begin{tabular}{|c|c|c|c|c|c|c|}
\hline & \multicolumn{2}{|c|}{ FGD } & \multicolumn{2}{|c|}{ IDI } & \multicolumn{2}{|c|}{ Total } \\
\hline & Number & $\%$ & Number & $\%$ & Number & $\%$ \\
\hline \multicolumn{7}{|l|}{ AGE } \\
\hline $15-19$ years & 42 & 33.1 & 3 & 21.4 & 45 & 31.9 \\
\hline $20-24$ years & 31 & 24.4 & 5 & 35.7 & 36 & 25.5 \\
\hline 25 - 29 years & 15 & 11.8 & 0 & 0.0 & 15 & 10.6 \\
\hline $30-34$ years & 16 & 12.6 & 4 & 28.6 & 20 & 14.2 \\
\hline $35-39$ years & 4 & 3.1 & 1 & 7.1 & 5 & 3.5 \\
\hline 40 years and more & 19 & 15.0 & 1 & 7.1 & 20 & 14.2 \\
\hline \multicolumn{7}{|l|}{ MARITAL STATUS } \\
\hline Single & 34 & 26.8 & 0 & 0.0 & 34 & 24.1 \\
\hline Married & 92 & 72.4 & 12 & 85.7 & 104 & 73.8 \\
\hline Widowed/Divorced & 1 & 0.8 & 2 & 14.3 & 3 & 2.1 \\
\hline \multicolumn{7}{|l|}{ LEVEL OF EDUCATION } \\
\hline Non schooling & 62 & 48.8 & 5 & 35.7 & 67 & 47.5 \\
\hline Primary & 27 & 21.3 & 4 & 28.6 & 31 & 22.0 \\
\hline Secondary/Professional & 33 & 26.0 & 5 & 35.7 & 38 & 27.0 \\
\hline Superior & 5 & 3.9 & 0 & 0.0 & 5 & 3.5 \\
\hline \multicolumn{7}{|l|}{ PROFESSION } \\
\hline Trader/saleswoman & 50 & 39.4 & 4 & 28.6 & 54 & 38.3 \\
\hline Housewife & 36 & 28.3 & 5 & 35.7 & 41 & 29.1 \\
\hline Pupil/student & 23 & 18.1 & 1 & 7.1 & 24 & 17.0 \\
\hline Seamstress/Hairdresser & 14 & 11.0 & 2 & 14.3 & 16 & 11.3 \\
\hline $\begin{array}{l}\text { Teacher/Computer } \\
\text { Scientist/Accountant }\end{array}$ & 4 & 3.1 & 2 & 14.3 & 6 & 4.3 \\
\hline
\end{tabular}


"Yes, women mainly come for vaccination and their children follow-up. On the other hand, others do not vaccinate their children in order not to fall sick. Newborns are often sent by their mothers or a family member. Usually, when the woman gives birth without any issue, she does not come back." [FGD women, 32 years old, Dubréka rural].

"Some women systematically return after giving birth for a check-up and at the same time vaccinate their children. Someone gives the child to another family member for vaccination. On the other hand, others only come back when they have issues." [IDI midwife, 30 years old, urban Dubréka].

\subsection{Barriers to the Use of Post-Natal Care Services}

Many barriers to the realization of postnatal care have been identified in the study:

\subsubsection{Financial Constraints}

These constraints are due to the low income of the community and the non-respect of free of charge of postnatal care services. Consequential effects are poor access to transport means and health facilities as well as high cost of drugs, as illustrated by participants in both rural and urban areas:

"Ahh it's not simple, we are beginners, my husband and I. It's tough to find something to eat, my husband is a labor, we live off the little things he gets and that doesn't cover all our needs, so we buy the medicine in the district to treat ourselves because we don't dare to go to the health center because everything is expensive there." (IDI woman 20 years old Dubréka urban).

"Due to lack of financial means, some women have issues attending the health center because their husbands have no means to cover the family's needs, the little they earn is just for the expenses. These women often like to use the decoction if they or their children get sick." [FGD young women, 23 years old, Dubréka rural].

\subsubsection{Barriers Related to Health Care Structures and Systems}

Distance from the health center and lack of transport means were the primary factors listed by participants. They impede the uptake of PNC services. For example, a young girl in a rural area in Kindia reported that: "Some women blame the distance from the health center for not doing PNC. I have a friend who lives very far from the health center, she became sick after giving birth and the doctor went to treat her at home. She returned to the health center only after a month" [FGD young women, 19 years old, Kindia rural].

This is also the opinion of a health care provider: "In some villages, motorbikes or hammocks are used as means of transport, so women have difficulty carrying babies on these means of transport over long distances, hence their refusal to use them. Only women who have many financial means can rent a car." [IDI midwife, 30 years old, urban Dubréka].

Furthermore, the lack of skilled health care providers, often filled by trainees, 
leads to insufficient of running some facilities and hamper on the use of PNC services.

"There are friends who complain that there are not enough agents at the health center. Those who are there don't treat well. They badly speak to the women. This is what many women in our community say. But I haven't had these problems with all my children." (IDI woman 30 years old, Dubréka rural).

\subsubsection{Barriers Related to Health Care Providers}

Participants noted poor reception in the health facilities. Some complained about the long wait before being consulted. Others reported in interviews their bad experiences during childbirth. This poor reception was sometimes linked to the non-payment of fees.

"When you go to the health center, the health workers badly talk to you as their children do. That's the only reason why I don't go there, I prefer to go elsewhere." [FGD women, 34 years old Kindia urban].

Health workers also give little importance to appointments and communication about the benefits of PNC according to women met. A hospital doctor reminded that hospitals in Guinea are authorized to perform childbirth, but PNC is only performed in health centers.

"What I noticed is that midwives do not inform women to return to a health center only for their post-natal consultation but also to vaccinate their babies mainly. But if they are not informed, they cannot come back." [IDI Doctor, 37 years old, urban Kindia].

Lack of trust and confidentiality between women and providers are others barriers related to Health care Providers. Some participants reported a lack of confidentiality among providers; this created doubt about the agent's efficiency, as well as a lack of confidence among women towards some providers.

"We come to the health staff to be treated and to tell secrets, whereas the staff who currently work in our health center here are not at all discreet and confidentiality does not exist because as soon as you finish the consultation your health problems are in the air." [IDI Woman, 20 years old, Kindiarural].

\subsubsection{Community Barriers}

The non-use of PNC services is also due to the fact that health care providers do not sensitize women on PNC benefits and do not inform them about secondary effects of children vaccination, as illustrated in these following quotes of a woman in a rural area and a midwife in an urban center facility:

"One day I sent my nephew for vaccination, the following day the vaccinated part had a blister and finally it became a wound. The child suffered, we didn't even sleep, since then I am afraid of sending the children for vac- 
cination.” [IDI woman, 30 years old, Dubréka Tanènè].

"Because of a lack of information, women think that if they give childbirth

in a health facility without problems, it is not necessary to return for a postnatal consultation." [IDI midwife, 30, urban Dubréka].

Cultural Constraints constitute also a non-negligible barrier for PNC such as the internment of the mother during the first post Partum's week, the proscription of the woman's sight by some men and marabouts, ...: "Some women also do not go to health center for the postpartum consultation on the pretext that there are men and some marabouts who should not see the newborn even if it is their own women, otherwise the mother or baby will die." [FGD young girls 19 years old, urban Kindia].

Another factor mentioned by the participants is the neglect to go to PNC, observed among some women who have just given birth, due to other housework or agricultural activities:

"Here, women are very negligent, even if the doctors schedule them for the postnatal care, they don't go. They are busy with other things, especially if their children are well." [FGD girls 18 years old Dubréka rural].

"Women here are busy doing their work instead of going to the health center after the childbirth. Some even go to their parents' homes after the naming ceremony, stay for a while so that their mothers can help them look after the child. This is not in their programme, they neglect post-natal care" [IDI woman 48 years old, urban Kindia].

\section{Discussion}

Our research reveals that postnatal care (PNC) is a major public health issue and there are many barriers to the use of these services. It notes that PNC services are used only in the event of complications or for child vaccination. Authors report that $77.8 \%$ of women in Nigeria and $97.7 \%$ in Ethiopia went to PNC to have their babies vaccinated [8] [9]. In Ethiopia, mothers with complications during childbirth got 2.58 times chance to use PNC services than those without complications during the same period [10]. Other authors related in Ethiopia, Nigeria and Uganda that for some women, the mother's apparent good health or the absence of symptoms of postpartum illness justified not using PNC services [4] [9] [11] [12]. Sometimes a sense of lack of importance of PNC prevailed [13] [14] or as reported in Kenya, that PNC was unnecessary because the childbirth step had already been completed [15].

Support during PNC is crucial for the mother and child's health. In our study in Guinea, most women go alone for PNC and are not accompanied by their husbands or other family members only if complications arise. Accompanying persons play a major role in women's decision-making for PNC. In Kenya, it was reported that spouses and parents had a strong influence on a woman's decision to opt for PNC, and they may also object [15]. Thus, women whose ability to 
make health decisions depends more on others than on themselves are less likely to engage in PNC [5] [9].

Our study shows that lack of financial means is an important barrier in the realization of PNC. Studies confirmed that women living in wealthier households achieve more PNC than those living in poorer households [14] [16] [17] [18] [19] [20]. In Guinea, Demographic Health Survey showed that the percentage of women receiving timely postpartum care increased from $30 \%$ in the lowest quintile to $70 \%$ in the highest quintile [2].

Distance from health facilities represents a barrier to the use of PNC services going from our results and those of other studies in Nepal, Ethiopia and Cambodia [18] [21] [22]. In Southern Sudan, when health facilities are remoted, access to routine maternal health services and emergency care is reduced due to the high costs of motorized transport and long distances [23]. In rural China, poor road conditions, long distances, and dispersed villages have negatively affected providers' ability to visit women at home [24]. This difficulty of geographical access is closely related to the means of transport. In Uganda, a mother had to wait two hours for the man on a motorcycle to drive her to the health center for a distance of about 30 minutes [25].

The study also revealed the non-availability of health care providers due to a lack of staff in the health system. In Indonesia, the workload of midwives was another bottleneck for postnatal care in villages because, in addition to providing perinatal care to the mother and child in the village and in the clinics, they also had to manage other child health programs in the center [26]. Also, in rural China, staff shortages have prevented maternal and child health workers from conducting postnatal home visits [24].

Poor attitudes of health providers such as poor reception and long waiting times before being checked by a health worker were reported in our study and by other authors in Nigeria, Kenya and Uganda [14] [15] [25]. In addition, the information-education component on care, hygiene and medication is not sufficiently developed by some providers during PNC [26]. As in our study, some authors have reported unpleasant experiences during prenatal care, childbirth and previous PNC as a barrier to using these services in Ethiopia, Nigeria and Guinea [9] [14] [17] [27].

Poor programming of PNC by health providers is a barrier to the non-implementation of PNC. Our study reveals that some health workers give very little importance on appointments and communication about the benefits of PNC. In Ethiopia, a common reason for lack of PNC is that health staff does not schedule women to return for postpartum care services within 42 days of birth [10]; in Uganda, mothers often received unclear messages from health providers about the timing of postpartum care and the services offered through voucher cards [25]. Doubt about competence and lack of confidence in the health worker, which can lead to childbirth outside health centers and sometimes at home, are other limiting factors identified in our study and by other authors in Indonesia [26]. In 
addition, many women child birthing at home do not perform PNC for fear of being reprimanded by health providers [20] [21] [28] [29] [30].

At the community level, several factors act as barriers to attending PNC services, such as lack of information/awareness in the community and particularly among pregnant women about the benefits of PNC and the positive effects of vaccination in children [10] [15] [16] [17]. In Indonesia, it was noted that most mothers and family members were unaware of the characteristics and duration of the postpartum period [26]. Many authors suggest that the antenatal and predischarge periods are opportunities for health care providers to emphasize the importance of PNC to women and their families [16] [17] [19].

Also, cultural barriers such as the confinement of women for the first 7 days postpartum in Guinea and 45 days in Ethiopia [17] are another reported factor. In Indonesia, these myths and rules are transmitted by parents, in-laws and other extended families [26]. Perceptions of femininity (coping with pain after childbirth) are rooted in cultural and traditional norms, as in Uganda [25]. Other authors report that in rural China, cultural barriers include embarrassment about being seen by a male provider [24].

\section{Strengths and Limitations of the Study}

This is the first study carried out in Guinea on this topic. It identified barriers related to the use of PNC services at all levels. This will facilitate the implementation of future strategies to address these barriers.

However, the study covered only two prefectures. Therefore, it did not focus on women who had given birth in the last two years but rather on women and girls of reproductive age in the community.

\section{Implication in Research and Practice}

A mixed (quantitative and qualitative) study of PNC, taking into account a greater number of variables and with wider application in other parts of the country allowing greater representativeness, would contribute to a better understanding of barriers to the use of postnatal care services.

The results of our study show that there is a need to define and integrate a package of activities for PNC in maternal and child health services. These activities should cover the sensitization of mothers on the importance and content of PNC during prenatal consultations and childbirth, as well as the training of health care providers in this area. In addition, the community should be sensitized on the removal of cultural barriers which prevent postnatal consultation and the need to carry it out in order to reduce maternal, neonatal and infant mortality.

\section{Conclusion}

The study identifies the main barriers to the use of postnatal consultations by women in Guinea. They are numerous and related to financial constraints and factors identified at the level of the health system, health providers and the com- 
munity. Improving the use of PNC services requires the removal of these barriers and the strengthening of the health system. It is at the price of a synergy of action involving all stakeholders that a drastic reduction of maternal, neonatal and infant mortality in the post-partum period can be achieved.

\section{Abbreviations}

ANC (Antenatal Care), DHS (Demographic and Health Survey), FGD (Focus group discussions, IDI (Individual in-depth interviews), PNC (Post-natal care), WHO/HRP (World Health Organization/UNDP/UNFPA/UNICEF/WHO/World Bank Special Programme of Research, Development and Research Training in Human Reproduction (HRP)).

\section{Funding}

This paper is a secondary analysis of data from a research study on "barriers to use of reproductive health services by women and girls in Guinea" which is funded by UNFPA in 2014.

\section{Conflicts of Interest}

The authors declare no conflicts of interest regarding the publication of this paper.

\section{References}

[1] Alkema, L, Chou, D, Hogan, D, Zhang, S, Moller, A.-B., Gemmill, A., et al. (2016) Global, Regional, and National Levels and Trends in Maternal Mortality between 1990 and 2015, with Scenario-Based Projections to 2030: A Systematic Analysis by the UN Maternal Mortality Estimation Inter-Agency Group. Lancet, 387, 462-474. https://doi.org/10.1016/S0140-6736(15)00838-7

[2] Institut National de la Statistique Ministère du Plan et du Développement Economique Conakry (2019) Enquête Démographique et de Santé 2018. Institut National de la Statistique Ministère du Plan et du Développement Economique Conakry, Guinée.

[3] World Health Organization (2014) WHO Recommendations on Postnatal Care of the Mother and Newborn. World Health Organization, Geneva.

[4] Wudineh, K.G., Nigusie, A.A., Gesese, S.S., Tesu, A.A. and Beyene, F.Y. (2018) Postnatal Care Service Utilization and Associated Factors among Women Who Gave Birth in Debretabour Town, North West Ethiopia: A Community-Based Cross-Sectional Study. BMC Pregnancy and Childbirth, 18, Article No. 508. https://doi.org/10.1186/s12884-018-2138-x

[5] Khaki, J.J. and Sithole, L. (2019) Factors Associated with the Utilization of Postnatal Care Services among Malawian Women Malawi. Medical Journal, 31, 2-11. https://doi.org/10.4314/mmj.v31i1.2

[6] Ministry of Health (Guinea) (2016) Standards and Procedures in Reproductive Health. Ministry of Health (Guinea), Conakry.

[7] World Health Organization (2007) The WHO Strategic Approach to Strengthening Sexual and Reproductive Health Policies and Programs. World Health Organization, Geneva. 
[8] Abota, T.L. and Atenafu, N.T. (2018) Postnatal Care Utilization and Associated Factors among Married Women in Benchi-Maji Zone, Southwest Ethiopia: A Community Based Cross-Sectional Study. Ethiopian Journal of Health Sciences, 28, 267-276. https://doi.org/10.4314/ejhs.v28i3.4

[9] Tesfahun, F., Worku, W., Mazengiya, F. and Kifle, M. (2014) Knowledge, Perception and Utilization of Postnatal Care of Mothers in Gondar Zuria District, Ethiopia: A Cross-Sectional Study. Maternal and Child Health Journal, 18, 2341-2351.

https://doi.org/10.1007/s10995-014-1474-3

[10] Limenih, M.A., Endale, Z.M. and Dachew, B.A. (2016) Postnatal Care Service Utilization and Associated Factors among Women Who Gave Birth in the Last 12 Months Prior to the Study in Debre Markos Town, Northwestern Ethiopia: A CommunityBased Cross-Sectional Study. International Journal of Reproductive Medicine, 2016, Article ID: 7095352. https://doi.org/10.1155/2016/7095352

[11] Solanke, B.L., Amoo, E.O. and Idowu, A.E. (2017) Improving Postnatal Check-Ups for Mothers in West Africa: A Multilevel Analysis. Women \& Health, 58, 221-245. https://doi.org/10.1080/03630242.2017.1292343

[12] Sacks, E., Tsitsi, B.M., Masvawure, L., Atuyambe, L.M., Neema, S., Macwangi, M., Simbaya, J. and Kruk, M. (2016) Postnatal Care Experiences and Barriers to Care Utilization for Home- and Facility-Delivered Newborns in Uganda and Zambia. Maternal and Child Health Journal, 21, 599-606. https://doi.org/10.1007/s10995-016-2144-4

[13] Ugboaja, J.O., Nwosu, O., Berthrand, N.O., Igwegbe, A.O. and OBI-Nwosu, A.L. (2013) Barriers to Postnatal Care and Exclusive Breastfeeding among Urban Women in Southeastern Nigeria. Nigerian Medical Journal, 54, 45-50. https://doi.org/10.4103/0300-1652.108895

[14] Olajubu, A.O., Olowokere, A.E., Ogundipe, M.J. and Olajubu, T.O. (2019) Predictors of Postnatal Care Services Utilization among Women in Nigeria: A Facility-Based Study. Journal of Nursing Scholarship, 51, 408-416. https://doi.org/10.1111/jnu.12473

[15] Ochieng, C.A. and Odhiambo, A.S. (2019) Barriers to Formal Health Care Seeking during Pregnancy, Childbirth and Postnatal Period: A Qualitative Study in Siaya County in Rural Kenya. BMC Pregnancy and Childbirth, 19, Article No. 339. https://doi.org/10.1186/s12884-019-2485-2

[16] Ayele, B.G., Woldu, M.A., Gebrehiwot, H.W., Gebre-egziabher, E.G., Gebretnsae, H., Hadgu, T., Abrha, A.A. and Medhanyie, A.A. (2019) Magnitude and Determinants for Place of Postnatal Care Utilization among Mothers Who Delivered at Home in Ethiopia: A Multinomial Analysis from the 2016 Ethiopian Demographic Health Survey. Reproductive Health, 16, Article No. 162.

https://doi.org/10.1186/s12978-019-0818-2

[17] Berhe, A., Bayray, A., Berhe, Y., Teklu, A., Desta, A., Araya, T., Zielinski, R. and Roosevelt, L. (2019) Determinants of Postnatal Care Utilization in Tigray, Northern Ethiopia: A Community Based Cross-Sectional Study. PLoS ONE, 14, e0221161. https://doi.org/10.1371/journal.pone.0221161

[18] Kaphle, H.P., Gupta, N., Bose, D.K., Paul, A., Singh, A. and Yadav, D.K. (2018) Factors Associated with Utilization of Postnatal Care in Myagdi District of Western Nepal. International Journal of Health Sciences \& Research, 8, 64-68.

[19] Somefun, O.D. and Ibisomi, L. (2016) Determinants of Postnatal Care Non-Utilization among Women in Nigeria. BMC Research Notes, 9, Article No. 21.

https://doi.org/10.1186/s13104-015-1823-3

[20] Rwabufigiri, B.R., Mukamurigo, J., Dana, R., Thomson, D.R., Hedt-Gautier, B.L. 
and Semasaka, J.P.S. (2016) Factors Associated with Postnatal Care Utilization in Rwanda: A Secondary Analysis of 2010 Demographic and Health Survey Data. BMC Pregnancy and Childbirth, 16, Article No. 122. https://doi.org/10.1186/s12884-016-0913-0

[21] Amare, Y., Scheelbeek, P., Schellenberg, J., Berhanu, D. and Hill, Z. (2018) Early Postnatal Home Visits: A Qualitative Study of Barriers and Facilitators to Achieving High Coverage. BMC Public Health, 18, Article No. 1074.

https://doi.org/10.1186/s12889-018-5922-7

[22] Kikuchi, K., Yasuoka, J., Nanishi, K., Ahmed, A., Nohara, Y., Nishikitani, M., Yokota, F., Mizutani, T. and Nakashima, N. (2018) Postnatal Care Could Be the Key to Improving the Continuum of Care in Maternal and Child Health in Ratanakiri, Cambodia. PLoS ONE, 13, e0198829.

https://doi.org/10.1371/journal.pone.0198829

[23] Izudi, J., Akwang, G.D. and Amongin, D. (2017) Early Postnatal Care Use by Postpartum Mothers in Mundri East County, South Sudan. BMC Health Services Research, 17, Article No. 442. https://doi.org/10.1186/s12913-017-2402-1

[24] Li, C., Wu, Q., van Velthoven, M.H., Zhang, Y.F., Zhang, S.Y., Li, Y., et al. (2014) Coverage, Quality of and Barriers to Postnatal Care in Rural Hebei, China: A Mixed Method Study. BMC Pregnancy and Childbirth, 14, Article No. 31.

http://www.biomedcentral.com/1471-2393/14/31

https://doi.org/10.1186/1471-2393-14-31

[25] Muwanguzi, D. (2018) A Qualitative Study of Barriers to Access and Use of Prepaid Postnatal Care Services among Mothers under the Reproductive Health Voucher System in Rural Uganda. Master's Thesis, Lund University, Lund.

[26] Probandaril, A., Arcita, A., Kothijah, K. and Pamungkasari, E.P. (2017) Barriers to Utilization of Postnatal Care at Village Level in Klaten District, Central Java Province, Indonesia. BMC Health Services Research, 17, Article No. 541. https://doi.org/10.1186/s12913-017-2490-y

[27] Balde, M.D., Bangoura, A., Diallo, B.A., Sall, O., Balde, H., Niakate, A.S., Vogel, J.P. and Bohren, M.A. (2017) A Qualitative Study of Women's and Health Providers' Attitudes and Acceptability of Mistreatment during Childbirth in Health Facilities in Guinea. Reproductive Health, 14, Article No. 4. https://doi.org/10.1186/s12978-016-0262-5

[28] Chaka, E.E., Abdurahman, A.A., Nedjat, S. and Majdzadeh, R. (2019) Utilization and Determinants of Postnatal Care Services in Ethiopia: A Systematic Review and Meta-Analysis. Ethiopian Journal of Health Sciences, 29, 935-944.

https://doi.org/10.4314/ejhs.v29i1.16

[29] Milkowska-Shibata, M.A., Aye, T.T., Yi, S.M., Oo, K.T., Khaing, K., Marlar, T., Win, T., Myo, S.Y., Toe, S.Y., West, H.S., Ringstad, K.M., Galarza, L., Meng, C. and Shibata, T. (2020) Understanding Barriers and Facilitators of Maternal Health Care Utilization in Central Myanmar. International Journal of Environmental Research and Public Health, 17, Article No. 1464. https://doi.org/10.3390/ijerph17051464

[30] Mohan, D., Gupta, S., LeFevre, A., Bazant, E., Killewo, J. and Baqui, A.H. (2015) Determinants of Postnatal Care Use at Health Facilities in Rural Tanzania: Multilevel Analysis of a Household Survey. BMC Pregnancy and Childbirth, 15, Article No. 282. https://doi.org/10.1186/s12884-015-0717-7 